\title{
Erratum to: Management of Craniomaxillofacial Injuries
}

Ghassan Soleiman Abu-Sittah, Joe S. Baroud, and Christopher Alain Hakim

\section{Erratum to:}

Chapter 3 in: G.S. Abu-Sittah et al. (eds.), Reconstructing the War Injured Patient, DOI 10.1007/978-3-319-56887-4_3

The book published without Christopher Alain Hakim being listed as a chapter author. He has been added to the chapter and the rest of the authors' names arranged in the proper order. The table of contents has been updated as well. 